\title{
LA SUBJETIVIDAD Y LA
}

FAMILIA QUE SUBYACEN EN LAS REFORMAS LEGISLATIVAS CONTEMPORÁNEAS

\section{Verónica Gómez Naar}

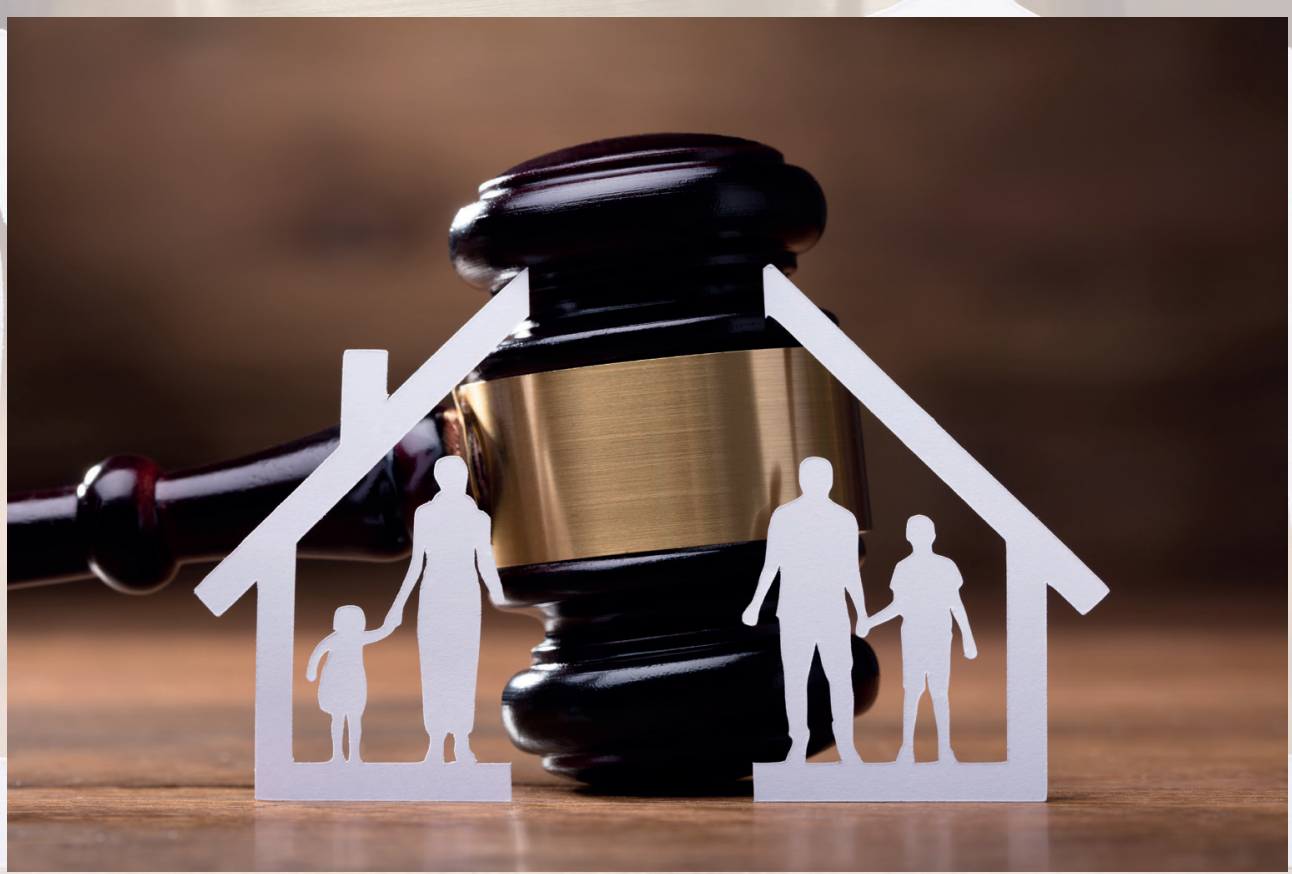





\title{
LA SUBJETIVIDAD Y LA FAMILIA QUE SUBYACEN EN LAS REFORMAS LEGISLATIVAS CONTEMPORÁNEAS
}

\author{
Verónica Gómez NaAR \\ Universidad de Buenos Aires
}

\section{Resumen}

Con el presente trabajo me propongo analizar, desde el punto de vista de la sociología, las concepciones de familia y de sujeto que predominan en la sociedad contemporánea occidental, pues el estudio de las categorías analíticas que aquella propone resultan de interés para el jurista, a efectos de abordar y comprender los grandes cambios legislativos de este siglo, en particular, los del Código Civil y Comercial argentino, aprobado por Ley 26.994, en vigencia desde el 1 de agosto de 2015. Desde el cambio de posicionamiento que significaron la obra de Descartes y las de otros filósofos que lo sucedieron, el hombre ${ }^{1}$ se ubicó en el centro de la escena del pensamiento y de la acción, en el lugar que antes ocupara "Dios", el "Creador" o la "Madre naturaleza". Se originó una nueva visión que transformó la realidad. Las ideas de progreso, los adelantos científicos y tecnológicos, la búsqueda personal directa de Dios (cisma protestante), la revaloración de la vida privada sobre la pública y el surgimiento de lo femenino, entre otros, condujeron a la aparición de un nuevo sujeto y de una familia "en desorden", ${ }^{2}$ a la que hay que rearmar y reconsiderar. El estudio de la transformación producida en esos dos ámbitos constituye un paso necesario para advertir en qué medida tales concepciones se encuentran implícitas en determinados cambios en la legislación.

Palabras clave: subjetividad, familia, patriarcal, feminismo, individualismo, capitalismo.

La autora: abogada. Doctoranda de la Universidad de Buenos Aires. Correo electrónico: gomeznaarv@ gmail.com

Recibido: 28 de noviembre 2019; Evaluado: 3 de abril 2020; Aceptado: 16 de abril 2020

Sustantivo que utilizaré como neutro referido a varón y mujer.

2 Élisabeth Roudinesco, La familia en desorden (Buenos Aires: Fondo de Cultura Económica, 2013), 167, 212 yss. 


\title{
SUBJECTIVITY AND THE FAMILY THAT UNDERLIE CONTEMPORARY LEGISLATIVE REFORMS
}

\author{
Verónica Gómez NaAr \\ Universidad de Buenos Aires
}

\begin{abstract}
These work seeks to analyze from a sociological perspective the conceptions of family and subject that predominate in contemporary Western society. The study of the analytic categories this proposes is interesting for the jurist, in order to approach and understand the important legislative changes of this century, in particular those of the Argentinean Civil and Commercial Code, approved in Law 26.994, in effect since August 1, 2015. Since the change of position that signified the work of Descartes and other philosophers that followed him, man $^{1}$ is located in the center of the scene of thought and action, in the place previously occupied by "God," the "Creator", or "Mother Earth." This gave rise to a new vision that transformed reality. The ideas of progress, scientific and technological advancements, the direct, personal search for God (Protestant schism), the revaluation of the private life over the public, and the emergence of feminism, among others, led to the appearance of a new

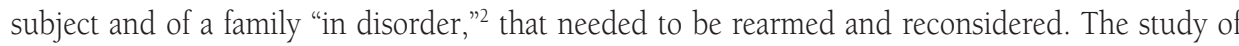
the transformation produced in these two spheres is a necessary step to advise to what extent these conceptions are implicit in specific legislative changes.
\end{abstract}

Keywords: subjectivity, family, patriarchal, feminism, individualism, capitalism

Author: Lawyer. Doctorate student at the University of Buenos Aires. Email: gomeznaarv@gmail.com

Received: November 28, 2019; Reviewed: April 3, 2020; Accepted: April 14, 2020

Noun I will use as a neutral to refer to men and women.

2 Élisabeth Roudinesco, La familia en desorden (Buenos Aires: Fondo de Cultura Económica, 2013), 167, 212, et seq. 


\title{
A SUBJETIVIDADE E A FAMÍLIA QUE SUBJAZEM NAS REFORMAS LEGISLATIVAS CONTEMPORÂNEAS
}

\author{
Verónica Gómez NAAR \\ Universidad de Buenos Aires
}

\section{Resumo}

Neste trabalho, proponho-me a analisar, do ponto de vista da sociologia, os conceitos de família e de sujeito que predominam na sociedade contemporânea ocidental, pois o estudo das categorias analíticas que aquela propõe são de interesse para o jurista, a fim de abordar e compreender as grandes mudanças legislativas deste século, em particular, as do Código Civil e Comercial argentino, aprovado pela Lei 26.994, em vigor desde $1^{\circ}$ de agosto de 2015. Desde a mudança de posicionamento que a obra de Descartes e as de outros filósofos que o sucederam significaram, o homem ${ }^{1}$ se situou no centro da cena do pensamento e da ação, no lugar antes ocupado por Deus, pelo Criador ou pela Mãe natureza. Foi originada uma visão que transformou a realidade. As ideias de progresso, os avanços científicos e tecnológicos, a busca pessoal direta por Deus (cisma protestante), a revalorização da vida privada sobre a pública e o surgimento do feminismo, entre outros, conduziram ao aparecimento de um novo sujeito de uma família em "desordem", a qual tem que se reorganizar e reconsiderar. O estudo da transformação produzida nos dois âmbitos constitui um passo necessário para observar em que medida esses conceitos se encontram implícitos em determinadas mudanças na legislação.

Palavras-chave: subjetividade, família, patriarcal, feminismo, individualismo, capitalismo.

A autora: advogada. Doutoranda da Universidad de Buenos Aires. E-mail: gomeznaarv@gmail.com

Recebido: 28 de novembro de 2019; avaliado: 3 de abril de 2020; aprovado: 16 de abril de 2020.

Substantivo que utilizo como neutro para me referir a homem e mulher. 


\section{Introducción}

Puede decirse, con cierta probabilidad, que para entender las modernas formas de pensar el derecho es necesario remontarse a Descartes, como bisagra entre las concepciones clásicas y las modernas. Con el Discurso del método, ${ }^{3}$ que refleja la parte central de la filosofía cartesiana, en cuanto signo del humanismo moderno que hace coincidir en el hombre el sujeto y el objeto del pensar, el pensamiento decanta en un racionalismo que será fuente de inspiración para los cultores de las escuelas racionalistas del derecho y para los positivistas kelsenianos. A partir de allí, el hombre deja de filosofar "desde" Dios para hacerlo desde sí mismo, atenido a su sola razón, lo cual no quiere decir que renegara de Dios: para ello habrá que esperar a Nietzsche.

Este cambio radical de perspectiva resulta de enorme trascendencia y da lugar a distintas corrientes de pensamiento propias de la Modernidad, de las que no escapa el ámbito jurídico.

En cuanto al nuevo ordenamiento normativo de la Argentina, sus características —en especial, el hecho de tener como fuente principal la propia jurisprudencia emitida por los tribunales- parecen indicar que estamos ante un cuerpo legal que, más que regular las relaciones humanas en su dimensión social, erige en ley las soluciones dadas a casos judiciales (arts. 1 y 3), ${ }^{4}$ lo cual conduce a una mayor judicialización de los conflictos humanos. Ello ubica al juez en un lugar de suprema relevancia, a lo que se suma el hecho de la discrecionalidad que le otorga el nuevo Código, a la hora de definir, aplicar e interpretar el derecho. Legislar según "lo razonable" implica dejar abiertas múltiples posibilidades y es el juzgador quien debe elaborar la prescripción normativa. En efecto, el derecho, por su propia definición, excluye lo irracional, o sea que aludir a "plazos razonables" o "sentencias razonables" es lo mismo que no definir nada. Surgen profundos interrogantes, por ejemplo, la cuestión de saber si el juez debe aplicar la ley o limitarse a buscar y argumentar "soluciones razonables".

3 René Descartes, Discurso del método. Reglas para la dirección de la mente (Buenos Aires: Hyspamérica, 1983), 58-62.

4 "Artículo 1. Fuentes y aplicación. Los casos que este Código rige deben ser resueltos según las leyes que resulten aplicables conforme con la Constitución Nacional y los tratados de derechos humanos en los que la República sea parte [...]. Artículo 3. Deber de resolver. El juez debe resolver los asuntos que sean sometidos a su jurisdicción mediante una decisión razonablemente fundada". República Argentina, Congreso de la República, Ley 26.994 de 2014, "Código Civil y Comercial de la Nación Argentina" (Buenos Aires: Boletín Nacional, 8 de octubre de 2014), arts. 1 y 3. 
En un gran número de materias, la nueva legislación sustantiva omite definir y brindar la solución legal, y obliga a los interesados a acudir a un juez: cuando alude al menor de edad "con edad y madurez suficiente" para la ejecución de determinados actos (como pedir que se agregue a su nombre el apellido del otro progenitor, art. 64, CCCN), quien debe decir si cuenta o no con madurez suficiente es el juez, lo mismo que para decidir si debe intervenir como parte del proceso de adopción, entre otros tantos ejemplos de indefinición que exigen una decisión de la justicia. Cabe preguntarse si, implícitamente, la nueva legislación presume un juez argumentativo en lugar de un juez que aplica la ley. Aquí se abre un espacio al análisis de las nuevas reflexiones sobre el razonamiento del juez y la motivación de la decisión judicial, que deberán centrarse en la figura que emana del estudio de los cambios que introduce el nuevo Código en los aspectos metodológicos y normativos.

Las categorías analíticas provenientes de la sociología resultan de sumo interés para el jurista en torno al entendimiento de los cambios legislativos de este siglo, como los que introduce el citado Código Civil y Comercial de la República Argentina, que fue aprobado por Ley 26.994 y entró en vigencia el 1 de agosto de 2015. En particular, lo referido a los dos aspectos reseñados (subjetividad y familia) guardan estrecha vinculación con la concepción individualista del ser humano que subyace en la regulación de determinados institutos, como cuando parece omitirse la contemplación del "otro" ("tú") que, en cuanto acreedor también del derecho consagrado en la norma, me compele a asumir las obligaciones que constituyen la contracara inescindible de esos mismos derechos; o del tercero que recibe o sufre los efectos del derecho allí reconocido; o la admisión implícita de una ética utilitarista y de un sistema social de capitalismo de consumo, entre otras indagaciones.

\section{Una nueva subjetividad}

\subsection{Individualismo}

Descartes es considerado el padre de la filosofía moderna, pues su obra expresó un auténtico giro copernicano en el pensamiento occidental y sentó las bases de la Modernidad. Obviamente, no ha sido un pensador solitario, sino el fruto de un contexto social, intelectual e histórico en el que florecieron grandes pensadores como Occam (anterior a Descartes, pero eslabón en la misma cadena del individualismo y voluntarismo), Hobbes, Spinoza, Montaigne, Bacon, Hume, Locke, Rousseau, Grocio y Suárez, entre otros. 
Podría decirse que la primera consecuencia de la filosofía de Descartes es el individualismo, el "yo" cartesiano que impone lo que Heidegger llamó "metafísica de la subjetividad". ${ }^{5}$ Nace un nuevo sujeto de la historia. Por otra parte, el ser del "yo" se identifica con el "pensar" (pienso, entonces soy), de donde emerge el racionalismo, entendido como teoría de la razón abstracta.

Otra consecuencia importante del cartesianismo es la negación del "otro", tanto individual como colectivo, que se desprende a partir de la distinción entre res cogitans y res extensa.

Sin duda son estos, junto con la idea de progreso indefinido de Compte, ${ }^{6}$ los elementos que caracterizarán a la Modernidad e insuflarán las nuevas expresiones de la organización social y jurídica.

La idea de Modernidad está estrechamente ligada a la de racionalización: ella hace de la razón el primer principio de la organización de la vida personal y colectiva, lo que supone la supresión de lazos sociales, de las costumbres y creencias tradicionales, así como la eliminación de las reglamentaciones y las protecciones corporativistas. ${ }^{7}$

También se halla asociada con la idea de secularización, entendida como desprendida de toda definición de fines últimos, pues la racionalidad se desenvuelve dentro de cada tipo de actividad y excluye que sean organizadas desde el exterior en función de su integración en un proyecto global, como lo implicaría un finalismo de tipo religioso. Asimismo, la sociedad reemplaza a Dios como principio de juzgamiento moral: es ella fuente de valores.

El bien reside en lo que es útil a la sociedad y el mal, en aquello que obstruye su desarrollo y eficacia. Así, la Modernidad señala el triunfo de la moral social, del utilitarismo y del funcionalismo. Pero la imagen weberiana de un mundo moderno racionalista termina por inquietar y crear un sentimiento de encierro, pues al romper la alianza y unidad entre el Cielo y la Tierra, se nos conduce a vivir en un mundo desencantado, privado de espiritualidad y de trascendencia. Cioran advierte también en el hombre moderno un utilitarismo y deseo de felicidad en este mundo que no calma la sed de lo absoluto y destaca la paradoja de que este individualismo es, al mismo tiempo, unificación de diversidades y deseo de

\footnotetext{
Martin Heidegger, ¿Qué es la metafísica? y otros ensayos (Buenos Aires: Fausto, 1996), 73-95.

Julián Marías, Historia de la filosofia (Madrid: Alianza, 1993), 340-344.

Bruno Oppetit, Droit et modernité (Paris: Presses universitaires de France, 1998), 3 y ss.
} 
anulación de visiones divergentes y complementarias, así como del derecho a ser diferente, a las particularidades; un mundo donde los hombres son moldeados de una misma materia. ${ }^{8}$

En tanto la Modernidad expresa la aparición del individualismo, el individuo se afirma en detrimento del sujeto político y con un predominio de la esfera privada sobre la pública.

En cuanto al derecho, esta nueva sociedad se caracterizará por centrar su legitimidad alrededor de este sujeto entendido como "individuo". Se conceptualiza al derecho como regla aceptada por todos (consenso o contrato). El derecho no prescribirá una conducta, sino más bien los límites a la acción humana, de suerte que la libertad de cada uno es respetada, en línea con Kant. ${ }^{9}$

\subsection{El "yo" narcisista y conquistador}

Otra característica de la subjetividad moderna es el narcisismo. El ser individual que nos describen los filósofos va a sumar una nueva condición a su personalidad, derivada del paso de la histeria al narcisismo a partir de la segunda mitad del siglo pasado. Ya no es el neurótico que se preocupa por lo que piensan o esperan los demás de él: le basta con mirarse y embelezarse consigo mismo. Edipo ha cedido su lugar a Narciso, quien pasa a encarnar el mito de una humanidad sin prohibiciones, fascinada por la potencia de su imagen. El tránsito de Edipo a Narciso, junto con el ascenso del hiperindividualismo, marcará a su vez el ocaso del padre. ${ }^{10}$

El sujeto moderno es también un ser escindido de su cuerpo y de su espíritu, en el que el énfasis está puesto en la autoconsciencia refleja y crítica, con desvalorización de la conciencia espontánea, aunque sea sapiencial. No se trata del pensamiento clásico que inducía al conocimiento de uno mismo, pues en la enseñanza socrática, el "yo" no es una entidad absolutamente independiente y desligada de la naturaleza y de su comunidad, como sí lo refleja la creencia moderna de "tener" un cuerpo

8 Se pregunta refiriéndose a Occidente: “¿Qué maldición le cayó para que al término de su desarrollo no haya producido más que esos hombres de negocios, esos abarroteros, esos tramposos de mirada nula y sonrisa atrofiada que uno encuentra por todas partes, tanto en Francia como en Inglaterra y en Alemania inclusive?". Emile Cioran, Historia y utopía (Barcelona: Tusquets, 1998), 34.

9 Immanuel Kant, Crítica de la razón práctica, 3a ed. (Madrid: Espasa-Calpe, 1984); La metafísica de las costumbres (Barcelona: Altaya, 1993).

10 Enrique del Percio, Ineludible fraternidad: conflicto, poder y deseo (Buenos Aires: Fundación Ciccus, 2014), 211. 
como un objeto separado, del cual se puede disponer (se legisla hoy "el derecho de disponer del propio cuerpo") o cuidar. Como observa Del Percio, para un miembro de cualquier otro pueblo de la historia es impensable la existencia de un yo sin cuerpo y sin alma. ${ }^{11}$

Este hombre moderno no solo es propietario de su cuerpo y de su alma, sino que conquista la naturaleza por medio de las ciencias y de la espada. Es alguien que no piensa que él existe porque es parte de una sociedad, sino que la sociedad existe porque él decide pactar con otros para constituirla. ${ }^{12}$

Esta separación también se marca profundizando la individualidad respecto a la comunidad en la cual vive este sujeto, a los demás seres vivos y a la naturaleza, pues ya no es su condición política (en el sentido de integrante de la polis) la característica específica que lo define y diferencia del resto de los seres animados. Lo que distinguía al hombre, para los griegos, era su relación con los demás hombres dentro de la ciudad, tan distinto al hombre de Kant, que debe su dignidad a la autonomía y a la posibilidad de darse a sí mismo las propias reglas; una substancia ensimismada y solitaria.

El hombre no occidental, como el de nuestros pueblos originarios de América, por el contrario, solo puede pensar en el ser o el "yo" como relación viviente con los otros y con la naturaleza toda. Para este modo de pensar, sentir y vivir, la relación es una categoría que antecede a la sustancia.

Algo similar intuyó Kierkegaard cuando nos reveló que el hombre era una síntesis de infinito y finito, de temporal y eterno, de libertad y necesidad; que la síntesis es la relación de dos términos y, por lo tanto, desde este punto de vista, el yo todavía no existe. ${ }^{13}$

\subsection{El niño mimado}

Con la declinación del poder paterno, que se hace evidente a partir de la década del sesenta del siglo pasado, el niño pasó a ocupar, en su relación con la madre, el lugar central antaño atribuido a "Dios padre". Valido de su omnipotencia, hereda

\footnotetext{
Enrique del Percio, Política o destino (Buenos Aires: Sudamericana, 2009), 216 y ss.

Del Percio, Ineludible, 169 y ss.

Sören Kierkegaard, Tratado de la desesperación (Buenos Aires: Leviatán, 1997), 19.
} 
una imagen confusa de la autoridad paterna, que parece disolverse en la nada de una maternalización creciente.

Cuando Hanna Arendt ${ }^{14}$ señala que la autoridad se ha esfumado del mundo moderno, se refiere a una crisis de autoridad, constante y cada vez más amplia y honda, que acompañó el desarrollo de nuestro mundo moderno en el siglo pasado y resalta que el síntoma más significativo radica en su expansión hacia áreas previas a lo político, como la crianza y la educación de los niños. En estos ámbitos, la autoridad, en el sentido más amplio, siempre se aceptó como un imperativo natural, exigido tanto por las necesidades naturales (la indefensión del niño) como por la necesidad política (la continuidad de una civilización establecida que solo puede perpetuarse si sus retoños transitan por un mundo preestablecido, en el que han nacido como forasteros). Así, explica que la autoridad siempre demanda obediencia y, por este motivo, es común que se la confunda con cierta forma de poder o de violencia, pero que, por el contrario, esta excluye el uso de medios externos de coacción: se usa la fuerza cuando la autoridad fracasa. Por otra parte, considera que autoridad y persuasión son incompatibles, porque la segunda presupone igualdad y opera mediante un proceso de argumentación:

Cuando se utilizan los argumentos, la autoridad permanece en situación latente. Ante el orden igualitario de la persuasión, se alza el orden de la autoridad, que siempre es jerárquico: la autoridad se diferencia tanto de la coacción por la fuerza como de la persuasión por argumentos, la relación autoritaria entre el que manda y el que obedece no se apoya en una razón común ni en el poder del primero, lo que tienen en común es la jerarquía misma, cuya pertinencia y legitimidad reconocen ambos y en la que ambos ocupan un puesto predefinido y estable. ${ }^{15}$

¿Quién podría dudar hoy de que la educación de los hijos está basada en una relación igualitaria de persuasión y no en una jerárquica de autoridad? Los padres no le ordenan al niño lo que debe hacer: le hablan y lo convencen acerca de la bondad de la conducta pretendida; utilizan la persuasión. Parece relevante analizar si la pérdida de la autoridad conlleva un riesgo de violencia, como advierte Arendt, es decir, la vinculación entre ambas; en todo caso, observar de qué manera el niño pasa de "niño dios" a "enfant terrible".

14 Hanna Arendt, Entre el pasado y el futuro: ocho ejercicios sobre la reflexión política (Barcelona: Península, 2016), 146 y ss.

15 Arendt, Entre el pasado y el futuro, 147. 
En ese mismo sentido, Sloterdijk destaca como características del hombre posmoderno, además del individualismo autocentrado que se elige a sí mismo como sector especial, el auge del "mimo" (el cuidado o mimo a uno mismo), mediante seguros privados, dietética, fitness, dinero fácil, biotécnica, formación sin esfuerzo, fama sin obra, seguridad sin lucha, etcétera. ${ }^{16}$

\subsection{El capitalismo de consumo}

Foucault ${ }^{17}$ se pregunta sobre la subjetividad moderna — cómo se construye el sujeto moderno- y lo hace con base en el capitalismo como contexto inescindible del cambio: por qué el sujeto piensa, ama y vive de determinada manera en estos tiempos del capitalismo. Recurre al estudio de la historia para concluir un panorama crítico y sombrío en el que el hombre, en cuanto construcción social de este tiempo, es un ser eminentemente productivo, dócil ante los dispositivos de poder.

El nuevo sujeto vive y actúa dentro de un sistema capitalista de consumo, donde se moldean sus deseos tanto como sus acciones. El sistema lo absorbe y lo obliga a formar parte, con la posibilidad de cuestionarlo desde el punto de vista ético, pero al cual debe someterse indefectiblemente.

\section{La deconstrucción de la familia}

Si miramos la realidad de nuestra época y las normas jurídicas que regulan la familia en nuestro país o, mejor dicho, las diversas posibilidades de familia (monoparental, homoparental, ensamblada, generada artificialmente, por afinidad, por voluntad procreacional), nos damos cuenta de que no se asemeja en nada a la familia clásica patriarcal, basada en la pareja heterosexual en la que la autoridad paterna reflejaba una relación jerárquica no solo entre padre e hijos, sino también entre padre y madre. Recordemos, a modo de ejemplo, que en el derecho argentino, hasta no hace mucho, el padre determinaba por sí solo el domicilio conyugal y el apellido familiar y, un poco más atrás, era el único con plena capacidad jurídica, hasta la Ley 11.357.

En un sentido amplio, la familia siempre se definió como un conjunto de personas ligadas entre sí por el matrimonio y la filiación e incluso por la sucesión de individuos

16 Peter Sloterdijk, En el mundo interior del capital (Madrid: Siruela, 2010), 254 y ss.
17 Michel Foucault, La verdad y las formas jurídicas (Ciudad de México: Gedisa, 1985), 37-59. 
descendientes unos de otros: un genos, un linaje, una dinastía, una casa o un oikos, para Aristóteles. ${ }^{18}$ La vida familiar está presente en prácticamente todas las sociedades humanas y dicho carácter universal suponía, por un lado, una alianza (el matrimonio) y, por otro, una filiación producto de la unión de un varón con una mujer, como fundamento biológico. Pero la institución también se apoyó en otro principio diferencial que aseguraba el paso de la naturaleza a la cultura, que consistía en el interdicto del incesto.

Roudinesco ${ }^{19}$ distingue tres grandes períodos en la evolución de la familia. En un primer momento, la llamada familia "tradicional", que sirve, ante todo, para asegurar la transmisión de un patrimonio; de allí que los casamientos se arreglaran entre los padres, sin tener en cuenta la vida afectiva y sexual de los futuros esposos, unidos en general a una edad precoz. En un segundo momento, entre fines del siglo XVIII y mediados del siglo XX, se impone el modelo de la familia "moderna", fundada en el amor romántico, por medio de la división del trabajo entre los cónyuges y pone a cargo del Estado la educación de los hijos. Russell destaca que la idea de que el matrimonio debería ser el resultado del amor romántico era una innovación revolucionaria que maduró a partir de la época de la Revolución francesa. ${ }^{20}$

Por último, a partir de la década de 1960, aparece la familia "contemporánea" o "posmoderna", que une por un período de extensión relativa a dos individuos en busca de relaciones íntimas o expansión sexual.

Al respecto, la autora citada se sorprende - y considera revelador de la transformación profunda que nuestra época ha generado en la familia— por la inédita situación del deseo homosexual convertido en deseo de "normatividad", de adoptar el modelo de familia otrora denostado, en el momento mismo en que los poderes del sexo parecen estar más extendidos que nunca en el corazón de una economía liberal, que tiende cada vez más a reducir al hombre a una mercancía.

Sin duda, esta familia contemporánea o posmoderna es el signo de la nueva subjetividad analizada antes: un hombre sin dios, sin tabúes, un niño rey que no reconoce la autoridad del padre, un ser escindido que "tiene" un cuerpo y derechos absolutos a su "proyecto de vida".

Roudinesco, La familia, 18.

Roudinesco, La familia, 19-20.

Bertrand Russell, Respuestas (Barcelona: Península, 1993), 229. 


\subsection{Irrupción de lo femenino}

A fines del siglo XIX, cuando Freud ${ }^{21}$ introduce en la cultura occidental la idea de que el padre engendra al hijo que será su asesino (complejo de Edipo), el tema del advenimiento de una posible feminización del cuerpo social ya es materia sustancial de un debate sobre el origen de la familia. Se plantea la disyuntiva entre patriarcado y matriarcado como dos modalidades de la nueva soberanía burguesa, con predominio de la idea de que la feminización del cuerpo social lo llevaría al desorden del apetito pasional con el que era identificada la mujer en el discurso misógino.

No obstante, aun cuando el padre de la soberanía burguesa ya no se parecía a un dios soberano - puesto que había sido derrocado con la abolición de la monarquía y el regicidio francés de 1793-, logra subsistir de un modo diferente: como patriarca de la empresa industrial.

El orden familiar económico burgués se asienta, entonces, en tres pilares, a saber: la autoridad del marido, la subordinación de las mujeres y la dependencia de los niños. En este contexto, la mujer debe ser, ante todo, una madre, a fin de que el cuerpo social esté en condiciones de resistir la tiranía de un goce femenino susceptible — se creía - de borrar la diferencia de los sexos. Si bien el dominio masculino se prolonga en esta nueva paternidad, la sustitución del poder del "dios padre" por el pater familias allanó el camino a una dialéctica de la emancipación, cuyas primeras beneficiarias serían las mujeres, y los niños tras ellas.

Freud también temió a la irrupción de lo femenino y algunos plantean la hipótesis de que reinventó el Edipo de la tragedia griega para responder de manera racional a dicho temor, toda vez que, con la ayuda del mito reconvertido en complejo, restablecía simbólicamente las diferencias necesarias para el mantenimiento de un modelo de familia que podía desaparecer. Mediante la represión (el superyó), se lograba preservar la ley de la diferencia entre los sexos, entre las generaciones, entre los padres y los hijos. Edipo es transformado por Freud en un sujeto culpable — como Hamlet—, aferrado a su neurosis y condenado a no ser ya sino el hijo de su madre y el rival de su padre. De esa manera, brinda al mundo occidental una teoría antropológica de la familia y la sociedad fundada en dos grandes elementos: la culpa y la ley moral.

21 Sigmund Freud, El yo y el ello. Tres ensayos sobre teoría sexual y otros ensayos (Madrid: Orbis, 1984), 124-141. 
Cabe considerar que la concepción freudiana de la familia fue el paradigma del surgimiento de la familia "afectiva" contemporánea, porque hace de esta una estructura psíquica universal en la que el amor y el deseo, el sexo y la pasión, se inscriben en el núcleo de la institución del matrimonio. Se apoya en una organización de las leyes de la alianza y la filiación que, a la vez que postula el principio de la prohibición del incesto y la confusión de las generaciones, lleva a cada hombre a descubrirse poseedor de un inconsciente y, por tanto, distinto de lo que creía ser, lo cual lo obliga a apartarse de cualquier forma de arraigo; en lo sucesivo, ni la sangre, ni la raza, ni la herencia pueden impedirle acceder a la singularidad de su destino. Culpable de desear a su madre y querer asesinar a su padre, se define como el actor de un descentramiento de su subjetividad.

\subsection{Búsqueda de la expansión sexual}

Si Freud pudo transferir a un nuevo orden simbólico la antigua soberanía patriarcal fue porque seguía apegado a la tradición de la llamada familia "autoritaria", pero también veía en ella la fuente de rebeliones futuras entre la autoridad y la libertad, la represión de los instintos y el advenimiento del deseo, el sometimiento y el conflicto. En ello tuvo razón, pues la erotización de la sexualidad fue a la par con una interiorización de las prohibiciones fundamentales características de las sociedades humanas. Freud estuvo así adelantado a su tiempo, aunque detrás de su propia innovación, ya que creía que jamás la civilización lograría desatar sin prejuicio los lazos entre el deseo sexual y la procreación.

Entre los dos movimientos —erotización y represión—Foucault ${ }^{22}$ toma partido por el primero, pero para Roudines $\mathrm{co}^{23}$ no son excluyentes y se traducen en una nueva organización de la familia basada en tres fenómenos notables: la revolución de la afectividad — que exige cada vez más la asociación del matrimonio burgués con el sentimiento amoroso y la expansión de la sexualidad femenina y masculina-; el lugar preponderante asignado al niño — cuyo efecto es la "maternalización" de la célula familiar—, y la práctica sistemática de una contracepción espontánea —que disocia el deseo sexual de la procreación y da origen, entonces, a una organización más individualista de la familia—.

Resulta notable cómo esta expansión de la sexualidad y la mirada puesta en la mujer y el niño dentro de la familia generó un ordenamiento inédito de las

22 Foucault, La verdad y las formas jurídicas, 143 y ss.

23 Roudinesco, La familia, 102 y ss. 
relaciones de alianza. En lugar de reducirse a su papel de esposa y madre, la mujer se individualizó, a medida que el acceso al placer se distinguía de la procreación. En cuanto al niño, se proyectó en una identidad diferente a la de sus padres. Ello condujo a una evolución de la sociedad que ratificó la declinación de la función paterna en beneficio de una autoridad parental compartida. Las normas jurídicas acompañaron esta declinación y despojaron paulatinamente al "jefe de familia" de sus prerrogativas.

A la par de ello, surgieron las luchas emancipadoras de la mujer por la igualdad de derechos, bajo la inspiración de un libro revolucionario publicado en 1949, El segundo sexo de Simone de Beauvoir. Esta obra daría origen a una nueva manera de plantear la diferencia de sexos, además de contener una crítica fulminante a las teorías de la sexualidad elaboradas por los hombres con el propósito de perpetuar su dominación sobre el cuerpo de las mujeres. Su famosa afirmación: "No se nace mujer, se llega a serlo" tuvo un efecto tan profundo que trascendió incluso el sentido subjetivo de su autora (el sexo de las mujeres no es la anatomía, es una cuestión política), para generar una dialéctica de construcción de la identidad sexual en la vivencia y la conciencia del sujeto.

Beauvoir, al situar la construcción de la identidad femenina del lado de la cultura y no de la naturaleza, llegaría a negar la importancia de la diferencia biológica de los sexos y, asimismo, desarrollaría la novedosa y escandalosa idea de separar la femineidad de la maternidad; el acto carnal, de la procreación; el deseo, de la reproducción. Lejos de remitir a las mujeres a su estado de madres, llega a rechazar el pensamiento de que la maternidad fuera otra cosa que una coacción ligada a una insatisfacción.

\subsection{El avance de las técnicas médicas y su influencia en la institución familiar}

De la mano de la emancipación de la mujer, los avances técnicos de la medicina posteriores a la Segunda Guerra Mundial inciden de manera sustancial en el nuevo ordenamiento familiar, al permitir que la disociación entre coito y procreación, entre sexo y maternidad, pase de la palabra y la psiquis a la realidad física. El surgimiento de métodos de contraconcepción (píldora anticonceptiva, dispositivos intrauterinos) brindan la posibilidad de regular los nacimientos. 
Por su parte, la instauración legal del divorcio lleva a la aparición de la familia "recompuesta" o "ensamblada", con profundas implicaciones desde el punto de vista sociológico, al desacralizar, por un lado, la institución del matrimonio y, por el otro, humanizar los lazos de parentesco, ya sobre un concepto diferente que no exige la consanguinidad.

En lo sucesivo, en el seno de esta familia contemporánea —-frágil y consciente de su desorden—, ${ }^{24}$ algunos hijos podrán ser criados bajo la autoridad de dos padres y de dos madres, y bajo el mismo techo que sus hermanastras o hermanastros.

En la década del setenta se introduce la expresión "familia monoparental" para designar, sin estigmatizarlo, a un modelo "irregular" de madre soltera. Las mujeres no solo habían conquistado el poder de satisfacer un placer distinto de la maternidad, sino también la posibilidad de controlar la cantidad de nacimientos y negarse a traer al mundo un número ilimitado de hijos.

A partir de allí, la familia no se considerará únicamente como una estructura del parentesco que prolonga la autoridad disuelta del padre y sintetiza el paso de la naturaleza a la cultura mediante las prohibiciones y funciones simbólicas, sino como un lugar de numerosos rostros donde el poder está ahora descentralizado. Esta familia se asemeja, para Roudinesco, "a una tribu insólita, una red asexuada, fraternal, sin jerarquía ni autoridad y en la cual cada uno se siente autónomo o funcionalizado". ${ }^{25}$ Cita a Durkheim, para ponderar que la institución familiar tiende a reducirse a medida que se extienden las relaciones sociales y se desarrolla el capitalismo, para dar origen al individualismo; la familia moderna se limita a padre, madre, hijos y sus descendientes, así como los hijos menores y los solteros. En ese modelo, el padre se reduce a una abstracción, pues es la familia —y no él- la que se encarga de los conflictos privados, mientras se introduce un concepto de parentesco disociado de la consanguinidad, que queda en segundo plano. ${ }^{26}$

En ese contexto, los progresos de la inseminación artificial constituyen un hito en el ámbito de la procreación y la filiación, puesto que, al reemplazar el acto sexual por una acción médica, van a conducir a la posibilidad de la fecundación del óvulo fuera del cuerpo de la madre y por medio de un semen no perteneciente al padre, lo que genera la necesidad de replantear por completo la institución del matrimonio.

\footnotetext{
Roudinesco, La familia, 165.

Roudinesco, La familia, 168.

Roudinesco, La familia, 113.
} 
Surgen los bancos de semen y la madre "portadora", con la paradoja de que esta comienza a ser incierta en el momento mismo en que el padre deja de serlo, pues la paternidad puede entonces ser demostrada por la ciencia.

Se dice con razón que las historias de madres portadoras son diferentes de los episodios vividos por los padres donantes de semen, pues el padre biológico no tiene ninguna experiencia concreta de la paternidad, mientras que la madre "prestada" lleva en su seno al niño y participa así, en su cuerpo, de la concepción del hijo. De allí surge una multitud de conflictos posibles. ${ }^{27}$ Estos son aún mayores, si se piensa en la violación del incesto o de las leyes de prohibición de la consanguinidad — por ejemplo, cuando una madre o una hermana es portadora del hijo de la hija o de la hermana, o la donación de semen entre consanguíneos-, en la clonación, en manipulaciones eugenésicas, etcétera.

Pero mientras mujeres y varones anhelan insertarse en el modelo de familia y engendrar hijos mediante técnicas médicamente asistidas por diversas razones -monoparentalidad, homosexualidad, esterilidad y hasta estéticas—, se observa un nuevo tipo de matrimonio o pareja que decide no tener hijos, sobre todo por motivos económicos o de disposición del tiempo, el cual representa el modelo paradigmático del capitalismo moderno y que ha sido descrito con la sigla DINK ("double income no kids"). Es una estructura de hogar donde se consigue el doble objetivo de que haya dos ingresos de dinero y la mujer pueda desarrollarse laboralmente y dejar de lado la maternidad como único fin de su existencia. ${ }^{28}$ Sin duda, ningún futuro puede ser el corolario de este eslogan, pues una comunidad que rehúsa al niño rechaza también el tiempo, aquello que durará después de nosotros; en definitiva, la elección por la vida. ${ }^{29}$

\section{La evolución del derecho y la nueva legislación civil argentina}

La evolución del derecho privado en la época contemporánea muestra, por un lado, un proceso inverso al de la codificación del siglo XIX, es decir, un desmembramiento o fraccionamiento de las fuentes que se descomponen en leyes particulares sobre objetos específicos —a veces de temas que están en el Código, pero pretenden

\footnotetext{
Roudinesco, La familia, 182.

28 Del Percio, Ineludible, 208.

29 Jean-Claude Barreau, Quelle morale pour aujourd hui... (París: Plon, 1994), 145
} 
primacía-, en normas comunitarias e internacionales, en principios emergentes de los convenios, tratados internacionales y de las mismas Constituciones, y en las disposiciones constitucionales que adquieren operatividad mediante lo que se ha dado en llamar la "constitucionalización" del derecho privado; ${ }^{30}$ todas esas fuentes son llamadas a "dialogar entre sí" para la interpretación y resolución de los conflictos. Se configura como un sistema policéntrico que desmonta poco a poco la codificación ("descodificación").

Al mismo tiempo, se observan cambios profundos desde el punto de vista cualitativo de lo que el derecho es, en particular en la regulación de las materias referidas a la familia y a la persona.

Muchos de esos cambios se relacionan con los principios sociológicos analizados que dan cuenta de un nuevo sujeto en su dimensión cultural y social, así como de una nueva estructura familiar, una familia en plena transformación.

Sin hacer juicios de valor sobre la bondad o conveniencia de algunos de esos cambios legislativos, sino con el propósito de entender el substrato sociológico de ellos, es posible relacionar algunas novedosas disposiciones con la consideración de un sujeto individualista y narcisista. Así ocurre, por ejemplo, con la voluntad procreacional como una nueva vía de engendrar los hijos (CCyCo, art. 562). Como su nombre lo indica, basta la voluntad de la persona y no es necesario que exista transmisión genética de uno o ambos progenitores. La norma valora el deseo de ser padre por encima de una realidad biológica y del deseo o de la voluntad de aquellos "otros" implicados (madre portadora, donante, el niño). Este cambio sustancial parece así responder a un hombre centrado en sí mismo, todopoderoso en el cumplimiento de sus deseos y de su proyecto de vida, lo cual se permite con las importantes transformaciones de la ciencia médica y las tecnologías que han incidido en la conducta y la cultura del hombre moderno.

Del mismo modo, las nuevas formas de parentesco se escinden de la realidad biológica y de los lazos de consanguinidad, para hacer realidad una familia diversa, que contiene múltiples posibilidades acordes con las nuevas circunstancias de una familia en deconstrucción: monoparentalidad, matrimonios igualitarios y familias ensambladas. La nueva figura de la adopción de integración se configura cuando

30 Rodolfo Luis Vigo, Constitucionalización y judicialización del derecho: del estado de derecho legal al estado de derecho constitucional (Bogotá: Ibáñez, 2012), 269 y ss. 
se adopta al hijo del cónyuge o conviviente, lo que genera vínculos jurídicos y de parentesco, así como deberes y derechos; ello atiende una realidad de familias ensambladas con hijos de uno y otro componente de la pareja, al igual que la creación de lazos de parentesco entre ellos, a saber: los progenitores e hijos afines con los deberes y derechos previstos en los Artículos 672 a 676 (CСyCo, art. 536). Del mismo modo, la familia monoparental se halla también contemplada en este ámbito, ya que el Artículo 599 del mismo Código autoriza expresamente la adopción por una única persona.

El divorcio denominado "exprés" (arts. 436 y ss.) permite disolver la unión matrimonial de forma casi inmediata, prescindiendo a veces del "otro" (el hijo o los hijos del matrimonio que pueden quedar sin acuerdo sobre quién tendrá el cuidado personal o si recibirán alimentos, entre otros aspectos), sin cuya resolución aún puede declararse el divorcio. Asimismo, el tercero perjudicado puede ser un acreedor al cual le afecte la falta de disolución de la comunidad de bienes. Cabe pensar que esta problemática habrá de ser prudencialmente salvada por los jueces de familia, aunque la ley es muy estricta en este punto. ${ }^{31}$

Esta nueva regulación legal del divorcio parece responder a cuatro aspectos ya analizados. Por un lado, se infiere un individuo en el cual predomina su propio interés y sus deseos, sin contemplar el interés del "otro" — sean los hijos, sea el mismo Estado- en la preservación de la unión familiar como célula de la sociedad. En segundo lugar, el matrimonio que se encuentra en la base de la regulación no es el matrimonio romántico del siglo XIX, sino el que modela la familia contemporánea a partir de 1960, desacralizado, y que enlazando a dos personas por un período con especial acento en la unión y el goce sexual al que alude Roudinesco en el ensayo ya comentado. En tercer lugar, surge un derecho absoluto e igualitario entre varón y mujer a obtener el divorcio del modo más simple y breve, lo cual se conecta con una dimensión cultural igualitaria alcanzada gracias a las luchas del feminismo a partir del siglo XX. Por último, se advierte un predominio de la esfera privada sobre la pública, ya que el Estado no debe inmiscuirse en las razones privadas de las personas para decidir la disolución de su matrimonio.

31 En Dinamarca advirtieron este problema y volvieron atrás con el proceso exprés de divorcio: establecieron un período de espera o reflexión de tres meses para todas las parejas con hijos menores de 18 años, con asistencia de psicólogos y mediadores para ayudarles a comunicarse y a resolver las cuestiones que atañen a los niños. 
En materia de la autoridad parental, la otrora "patria potestad" ha pasado a denominarse "responsabilidad parental", cambio lingüístico que, por sí solo, muestra una nueva visión del instituto legal y de la realidad subyacente. La familia patriarcal basada en la autoridad del padre no es el ámbito doméstico contemplado en la nueva normativa, sino la familia contemporánea en la cual el padre y la madre tienen igual responsabilidad y derecho en relación con sus hijos, tal como se dispone en los Artículos 641, 646 y siguientes del nuevo ordenamiento. El término "progenitor" que este emplea permite referirse tanto al varón como a la mujer que procrean, las parejas del mismo género y la familia monoparental. El varón se encuentra en paridad, lo que surge, por ejemplo, del cuidado personal compartido como primera alternativa que tiene el juez en el momento de otorgarlo (art. 651). ${ }^{32}$ La mujer es mirada en igualdad respecto al varón en lo relativo al ámbito doméstico y laboral, por lo que el Artículo 660 prescribe que las tareas cotidianas que desempeña el progenitor (varón o mujer) que tiene el cuidado personal del hijo tienen un valor económico y constituyen un aporte a su manutención; esto también se evidencia en el nuevo Artículo 666, que basa la obligación alimentaria, en el caso de cuidado compartido, en la equivalencia de recursos con los que cuentan ambos progenitores a partir de una concepción igualitaria según la cual tanto el varón como la mujer trabajan y obtienen ingresos.

Por otra parte, el hijo adquiere mayor capacidad de hecho al ponderar su grado de madurez para tomar decisiones (principio de autonomía progresiva, art. 639, inc. b) ${ }^{33}$ dentro de un esquema filosófico kantiano en el que lo central del hombre es su libertad y su autonomía. A su vez, los principios rectores que deben guiar el ejercicio de la responsabilidad parental (interés superior del niño, autonomía progresiva y derecho del niño a ser oído y a que su opinión sea tenida en cuenta, art. 639), ${ }^{34}$ la necesidad del consentimiento expreso del hijo adolescente para un viaje al extranjero, el cambio de residencia o la administración de sus bienes (CCyCo, art. 645), y la intervención del juez en múltiples situaciones de desacuerdo entre los progenitores propugnando el acceso a la justicia del hijo con madurez suficiente indican un importante cambio de paradigma en el que la autoridad de los progenitores se ve diluida y se vislumbra una inclinación hacia una educación igualitaria de persuasión, en términos de Arendt. ${ }^{35}$

República Argentina, Congreso de la República, Ley 26.994 de 2014, art. 651.

República Argentina, Congreso de la República, Ley 26.994 de 2014, art. 639, inc. b.

34 República Argentina, Congreso de la República, Ley 26.994 de 2014, art. 639.

35 Arendt, Entre el pasado y el futuro, 148. 
Por último, a modo de ejemplos que sostienen las hipótesis planteadas en este trabajo, se observa que los reseñados principios de libertad y autonomía, junto con la subjetividad "escindida" de la que nos habla Del Percio, ${ }^{36}$ se ven reflejados en nuevas figuras como los actos de disposición del propio cuerpo (CСyCo, art. 56) o la directivas médicas anticipadas (art. 60), ${ }^{37}$ y la concepción consensualista en el ámbito de validez del derecho y de autorregulación, que se manifiesta en diversas disposiciones como las concernientes al apellido de los hijos (CCyCo, art. 64) o los pactos de convivencia (CCyCo, arts. 513 y 514).

\section{Conclusiones}

Nuestra época es el reflejo de cambios radicales e incesantes que han trastocado una institución básica de la comunidad como es la familia, cuyo devenir es aún incierto, pero nos pone en una posición de observación y abierta comprehensión, con la expectativa de que encierre los valores de una humanidad más "humana", más justa, solidaria e inclusiva. El problema sería definir estos términos, pero esa es harina de otro costal.

El nuevo Código argentino no es ajeno a estas transformaciones; por el contrario, es el fruto mismo del sujeto moderno occidental en devenir, de su experiencia vivencial, su cultura, sus contradicciones y sus angustias, quien vive en una comunidad con un orden doméstico o familiar en plena transformación.

Lo cierto es que las múltiples posibilidades de procreación, de parentalidad y de parentesco que se abren con las innovaciones técnicas de la medicina genética y procreacional abren profundos interrogantes éticos. No obstante, la velocidad de los cambios, la urgencia con la que se presentan las necesidades y los deseos a satisfacer en el sujeto contemporáneo y otros factores suscitan una postergación del análisis de estos cuestionamientos en pos de la inmediata experimentación y consagración de los "avances" científicos a costa del desorden y, lo más preocupante, los daños que puedan ocasionar y los derechos que puedan vulnerar. Esta realidad arrojada a la existencia recibe luego la convalidación de las normas jurídicas, en un difícil juego de equilibristas por rearmar una familia, una parentalidad, un nombre, una nacionalidad y una identidad, o en el que necesariamente unos derechos pierden y otros ganan, en la medida en que se tiene presente que existe el "otro".

\footnotetext{
36 'Así, se habla por ejemplo del 'derecho a disponer del propio cuerpo' como si el cuerpo fuera una propiedad del yo con existencia independiente", en Del Percio, Política, 216.

37 República Argentina, Congreso de la República, Ley 26.994 de 2014, art. 60.
} 
De tal modo, es posible pensar, con Lyotard, ${ }^{38}$ que lo que se denomina investigación y desarrollo en la sociedad contemporánea — cuyos resultados no dejan de provocar conmociones en nuestro medio- constituyen procesos por los que la especie humana es empujada "hacia adelante", sin tener la menor capacidad de dominarlos, que distan mucho de ser la obra del genio humano consagrado a descubrir lo verdadero y a hacer el bien. ${ }^{39}$

Ante este panorama —y, si es como dicen, que los pueblos "desmoralizados" no tienen un futuro- la gran cuestión que planteó el antiguo consejero cultural de Mitterrand será entonces volver a darle un "alma" a la Modernidad, a fin de que no se destruya ella misma. ${ }^{40}$

\section{Referencias}

Arendt, Hanna. Entre el pasado y el futuro: ocho ejercicios sobre la reflexión politica. Barcelona: Península, 2016.

Barreau, Jean-Claude. Quelle morale pour aujourd hui... París: Plon, 1994.

Cioran, Emil. Historia y utopía. Barcelona: Tusquets, 1998.

Del Percio, Enrique. Ineludible fraternidad: conflicto, poder y deseo. Buenos Aires: Fundación Ciccus, 2014.

Del Percio, Enrique. Politica o destino. Buenos Aires: Sudamericana, 2009.

Descartes, René. Discurso del método. Reglas para la dirección de la mente. Buenos Aires: Hyspamérica, 1983.

Foucault, Michel. La verdad y las formas jurídicas. Ciudad de México: Gedisa, 1985.

Freud, Sigmund. El yo y el ello. Tres ensayos sobre teoría sexual y otros ensayos. Madrid: Orbis, 1984.

Heidegger, Martin. ¿Qué es la metafisica? y otros ensayos. Buenos Aires: Fausto, 1996.

Kant, Immanuel. Crítica de la razón práctica, 3a ed. Madrid: Espasa-Calpe, 1984.

Kant, Immanuel. La metafísica de las costumbres. Barcelona: Altaya, 1993.

Kierkegaard, Sören. Tratado de la desesperación. Buenos Aires: Leviatán, 1997.

Lyotard, Jean-Francois. Lo inhumano. Buenos Aires: Manantial, 1988.

Marías, Julián. Historia de la filosofía. Madrid: Alianza, 1993.

Oppetit, Bruno. Droit et modernité. Paríis: Presses Universitaires de France, 1998.

República Argentina, Congreso de la República. Ley 26.994 de 2014, "Código Civil y Comercial de la Nación Argentina". Buenos Aires: Boletín Nacional, 8 de octubre de 2014.

\footnotetext{
Jean-Francois Lyotard, Lo inhumano (Buenos Aires: Manantial, 1988), 71

Lyotard, Lo inhumano, 68.

Barreau, Quelle morale pour aujourd hui..., 46.
} 
Roudinesco, Élisabeth. La familia en desorden. Buenos Aires: Fondo de Cultura Económica, 2013.

Russell, Bertrand. Respuestas. Barcelona: Península, 1993.

Sloterdijk, Peter. En el mundo interior del capital. Madrid: Siruela, 2010.

Vigo, Rodolfo Luis. Constitucionalización y judicialización del derecho: del Estado de derecho legal al Estado de derecho constitucional. Bogotá: Ibáñez, 2012. 